\title{
Application of Redecision Therapy in Executive Coaching Workshops: Part 2 - A Qualitative Exploration of Participants' Changes
}

\author{
(C) 2014 Mark Widdowson \& Mil Rosseau
}

\begin{abstract}
This is the second paper of three and describes an investigation into the way that executive coaching as a growing field of organisational development can be based on transactional analysis theory and methods. Twelve participants who had attended a coaching workshop based on Goulding \& Goulding's (1979) redecision therapy approach completed a follow-up Change Questionnaire adapted by the first author from material by Elliott et al (2001) and responses were analysed using thematic analysis (Braun \& Clarke 2006). Participants reported experiencing a wide range of personal growth experiences, positive interpersonal change and growth in their business, managerial and leadership skills as a result of participating in the workshops. Limitations are described including the possible impact of the transferential artefact of wanting to please the workshop facilitator. The thematic analysis findings suggest that such an approach can provide an effective framework for executive coaching workshops.
\end{abstract}

\section{Keywords}

executive coaching, redecision therapy, qualitative research, thematic analysis, transactional analysis

\section{Introduction}

Executive coaching is a blossoming field, which has been widely implemented across a range of business contexts. Despite the wide use of coaching, the evidence base for its effectiveness is still in the relatively early stages of development (Kampa-Kokesch \& Anderson, 2001). Much of the effectiveness research which has been conducted so far appears to have focused on the impact coaching has on performance enhancement and improved efficiency/ output within the business. Olivero et al. (1997) found that participants in a coaching programme reported greater personal growth and improved work performance. Coaching has also been found to be effective at improving interpersonal relationships, self-efficacy, and personal responsibility, all of which improve overall work functioning and increased personal well-being. Furthermore coaching tends to have high levels of client satisfaction and is largely well-regarded and valued by executives (KampaKokesch et al 2001; Evers at al, 2006). Coaching has also been demonstrated to be an effective method of leadership development, with participants experiencing positive changes in management skills, improved workbased interpersonal relationships, increased productivity and goal setting (Kombarakan et al 2008) and increased effectiveness in business meetings (Perkins, 2009).

There is strong similarity between coaching and the fields of counselling and psychotherapy. This makes sense; all three are activities which rely on the use of psychological theory and method to promote personal change and transformation. Much coaching practice seems to be based on cognitive-behavioural or psychodynamic principles (Kampa-Kokesch \& Anderson, 2001). Probably the biggest difference exists in the area of the purpose or intention of these activities. In executive coaching, the focus is specific and goal-directed and is on enhancing individual $s$ personal development to promote positive changes in their work performance. This is in contrast to counselling or psychotherapy where the intention is the resolution of a specific personal problem and may be more exploratory in nature (Hart et al, 2001).

Although there is strong similarity between coaching, counselling and psychotherapy (and indeed many practitioners work in more than one of these fields), we do not consider these to be equivalent activities, nor do 
we make the assumption that professionals in one field are automatically qualified to work in others, and we acknowledge that each field requires a specific and specialist set of competencies and knowledge.

Several relevant studies have investigated the outcome of transactional analysis redecision therapy groups, all of which report positive findings. McNeel (1982) examined the outcomes of a two day redecision therapy marathon group ( $n=15)$ and found that participants experienced the group as a positive experience which had led to greater personal growth which was sustained at a three-month follow-up interval. Unfortunately, McNeel's study did not use standardised outcome measures so it is difficult to precisely determine the nature or extent of the changes. A study by Boholst (2003) recruited 28 participants, 15 of whom attended a five-day transactional analysis therapy marathon group, whilst 13 formed a no-intervention control group. Once again, standardised outcome measures were not used, although participants were both self and peer-rated as having improved their communication and interpersonal style. This improvement followed a pattern which corresponded to changes relating to the functional model of transactional analysis theory; that is, participants experienced a reduction in Controlling Parent and Adapted Child and an increase in Nurturing Parent, Free Child and Adult interpersonal modes. A study conducted by Noriega Gayol (1997) also examined the outcomes of a one-week intensive transactional analysis psychotherapy group ( $\mathrm{n}$ $=21$ ). The group was based on the transactional analysis principles of contracting, self-reparenting and redecision therapy. Several measures were used, including a prepost Coopersmith (1981) Self-Esteem. The results demonstrated statistically significant improvement in self-esteem ( $p=0.01)$ which was maintained at three month follow-up. These three studies suggest that a transactional analysis redecision-based group intervention helps participant to improve communication style, increase their self-esteem and enhance their personal development.

\section{The Context}

The research gathered data from group workshops facilitated by the second author, who works as an executive coach in a range of large international companies. More information about the nature of these workshops is provided in the first paper (Rosseau et al 2014).

The workshops were held in 19 different countries (15 European, 1 Asian, 2 African and 1 Middle Eastern). In total 192 participants attended; an average of 10 participants in each group across the 19 workshops. Participants were aware that research was being conducted on the process and outcome of the workshops and consented to participating in the research and to publication of anonymised data. This included consent from those returning questionnaires to use their data and the consent of all participants to use data from their workshop evaluation forms. The follow-up period was between 10 and 24 months after participation in the workshop. The length of time provides confirmation on the stability and endurance of the changes made by participants.

The workshops are intensive three-day groups which integrate methods from all four fields of specialisation in transactional analysis. The structure is based on the Goulding and Goulding (1979) three-part process; contracting, impasse clarification and redecision. The first part of the group is focused on participants establishing their contract goal for the workshop. This is then followed by an educational phase where individuals identify and clarify issues and areas for development. The content of this includes: ego states, enhancing communication, assertiveness training, negotiation and leadership skills, problem-solving, learning theory, basic neuroscience and script theory. Additional mini lectures are provided according to the specific needs of the participants. After this, participants move into the redecision phase. This is an individually-tailored process where participants are guided through the use of redecision methods to make personal changes and overcome specific obstacles which prevent their optimal personal and professional functioning (see Rosseau et al 2014).

\section{Aims}

The aims of the research were to examine:

- The level of participant satisfaction with the workshop.

- The changes participants experienced as a result of the workshop

- The specific elements of the workshop the participants found most useful

\section{Research Protocol}

At the end of each workshop, participants had completed a feedback form which included a 10 point Likert scale for satisfaction (0 represented total dissatisfaction and 10 represented completely satisfied). Participants were asked to provide a score according to the impact of the workshop, the applicability of the workshop, and whether they would recommend the workshop to their colleagues. Written evaluations had been received from 192 participants (100\% return) and these were analysed to examine the overall extent of participant satisfaction in the workshops; a summary of results are shown in Table 1.

A sample of twelve workshop participants were then contacted by e-mail, selected on the basis that they had explicitly stated in the workshops that they would be happy to participate in research and complete a followup interview or questionnaire (thus ensuring informed consent had been attended to). Participants were also 
Table 1: Analysis of Feedback Forms

\begin{tabular}{|c|c|c|c|c|c|c|c|c|}
\hline Country & $\begin{array}{c}\text { No of } \\
\text { participants }\end{array}$ & $\begin{array}{c}\text { e-mail } \\
\text { contacted }\end{array}$ & Impact total & $\begin{array}{l}\text { Impact } \\
\text { average }\end{array}$ & $\begin{array}{c}\text { Applicable } \\
\text { total }\end{array}$ & $\begin{array}{l}\text { Appicable } \\
\text { average }\end{array}$ & $\begin{array}{l}\text { Recommend } \\
\text { total }\end{array}$ & $\begin{array}{l}\text { Recommend } \\
\text { average }\end{array}$ \\
\hline EUROPEAN & 144 & & & & & & & \\
\hline Belarus & 9 & & 78 & 8.67 & 81.0 & 9.00 & 77.0 & 8.56 \\
\hline Belgium & 13 & & 115.5 & 8.88 & 118.0 & 9.08 & 115.0 & 8.85 \\
\hline Denmark & 8 & 1 & 68 & 8.50 & 72.0 & 9.00 & 68.0 & 8.50 \\
\hline Finland & 9 & 1 & 80.5 & 8.94 & 81.0 & 9.00 & 77.0 & 8.56 \\
\hline France & 12 & & 107 & 8.92 & 109.0 & 9.08 & 105.0 & 8.75 \\
\hline Georgia & 13 & & 114 & 8.77 & 118.5 & 9.12 & 113.0 & 8.69 \\
\hline Germany & 10 & 1 & 88 & 8.80 & 89.5 & 8.95 & 85.0 & 8.50 \\
\hline Holland & 8 & 1 & 71 & 8.88 & 72.0 & 9.00 & 68.0 & 8.50 \\
\hline Poland & 7 & & 62.5 & 8.93 & 63.5 & 9.07 & 64.0 & 9.14 \\
\hline Russia & 12 & 1 & 108.2 & 9.02 & 107.5 & 8.96 & 108.0 & 9.00 \\
\hline Spain & 6 & & 54 & 9.00 & 54.0 & 9.00 & 54.5 & 9.08 \\
\hline Sweden & 5 & 1 & 44.5 & 8.90 & 45.5 & 9.10 & 45.0 & 9.00 \\
\hline Switzerland & 12 & 1 & 107 & 8.92 & 108.0 & 9.00 & 102.0 & 8.50 \\
\hline UK & 8 & 1 & 69 & 8.63 & 71.5 & 8.94 & 71.0 & 8.88 \\
\hline Ukraine & 12 & & 108 & 9.00 & 108.0 & 9.00 & 109.0 & 9.08 \\
\hline \multicolumn{9}{|l|}{ ASIAN } \\
\hline Kazachstan & 14 & 1 & 125 & 8.93 & 127.0 & 9.07 & 126.0 & 9.00 \\
\hline AFRICAN & 23 & & & & & & & \\
\hline Kenya & 10 & 1 & 89 & 8.90 & 90.0 & 9.00 & 85 & 8.50 \\
\hline South Africa & 13 & 1 & 116 & 8.92 & 116.0 & 8.92 & 119.1 & 9.16 \\
\hline \multicolumn{9}{|l|}{ MIDDLE EAST } \\
\hline Saudi Arabia & 11 & 1 & 98 & 8.91 & 100.0 & 9.09 & 100.5 & 9.14 \\
\hline TOTAL & 192 & 12 & & & & & & \\
\hline
\end{tabular}

required to have a good standard of written English. In the case where more than one group member met both these criteria, one was randomly selected.

The e-mail explained the nature of the research, and the subjects were asked to complete and return an anonymised questionnaire (no identifying details were recorded on these forms). Surprisingly, there was once again a $100 \%$ response rate to the request.

The Change Interview used is a semi-structured interview schedule which was developed for psychotherapy research and which invites research participants to reflect upon the changes they have experienced during the course of psychotherapy and to identify their understanding of the causal factors in their own change process (Elliott et al 2001). The change interview format was adapted for a questionnaire format by the first author (see Appendix 1) and this was e-mailed out to the 12 selected subjects.

Qualitative data from the Change Questionnaire was analysed by the first author using Braun and Clarke's (2006) Thematic Analysis method. This is an inductive qualitative analysis approach. Participant responses were examined and concepts were identified. These 
were converted into codes, which were then subjected to constant comparison to identify over-arching themes. Quotes which illustrate these themes have been presented in the results below.

The literature review was not conducted until after the data analysis had taken place. This was to ensure that no a priori assumptions were made or that any existing literature would cloud the data analysis process.

\section{Results \\ "Phenomenal", "mind blowing", "life changing", "unusual" and "very effective"}

All 192 group participants had provided feedback for the workshop and the results are indicated in Table 1. These were unanimously positive and suggested participants had high levels of satisfaction with the workshop. Overall scores on How impactful was this workshop? ranged between 8.5 and 9.02 . Scores relating to the applicability of the workshop ranged between 8.93 and 9.12. The score for whether participants would recommend the workshop to colleagues ranged between 8.49 and 9.16. This suggests that participants had a high level of overall satisfaction with the workshop. A number of participants also provided additional unsolicited feedback on their forms which stated that they had felt sceptical about the workshop at the beginning but that their perceptions changed as they started to become aware that they were witnessing and experiencing personal change during the workshop.

Change Questionnaire Feedback

The feedback from the Change Questionnaire respondents was also unanimously positive about the impact and effectiveness of the workshop. The responses can be grouped into four superordinate categories; internal changes, interpersonal changes, enhanced leadership skills and helpful aspects of the workshop. These are illustrated in Figure 1.

The following quote was typical of the majority of the respondents, who reported positive changes linking to several of the superordinate themes:

I'm happier in my job and in my life. I feel stronger and more self-confident than ever before. Also, my relationships with friends, family and colleagues has improved a lot. I feel more of a leader.

Superordinate Theme 1: Internal Changes

All participants reported a series of internal changes which resulted in a greater sense of personal well-being.

The training effects were multiple: a higher selfawareness, better engaging skills and a lot less frustration coming from managing relationships
I am more confident in connection with difficult decisions regarding people.

I am more balanced, satisfied and am trying to relax whenever I can

The exercises with the ego states gave me good insights to different people I worked with it that point in time - and to myself in different situations both now and then

\subsection{Enhanced Self-Awareness}

Participants commonly reported a deeper level of selfawareness which tapped into their own personal issues and helped them to become aware of the origins of their way of being:

The most important outcome for me personally was to understand the root causes of my behaviours and thinking patterns.

This theme was expressed by most of the participants who appreciated a level of depth to their increased understanding. It would seem that identifying and working with each individual $s$ life experiences and issues enabled participants to make use of the workshop to promote their own path of self-development:

Overall what I found useful about this training was the fact that it went into the personal. It didn't just face the surface wanting to give solutions to symptoms . . . It analysed the root cause and built a path of development that was very personal

Many participants reported a substantially increased sense of self-awareness as a direct result of the group format and opportunities for receiving and reflecting on interpersonal feedback:

The training made me see how others perceived me and how little I was willing to do to meet new people.

It is possible that this process was mediated through an opportunity to receive live and direct 360 degree feedback from a range of colleagues whilst simultaneously reflecting on this.

1.2 Increased sense of Well-Being

All participants reported an increased sense of overall well-being which had a wide impact on many areas of their life; as quoted for above.

I'm happier in my job and in my life. I feel stronger and more self-confident than ever before. Also, my relationships with friends, family and colleagues have improved a lot

Since the course I have been happier than ever before I feel good about myself 


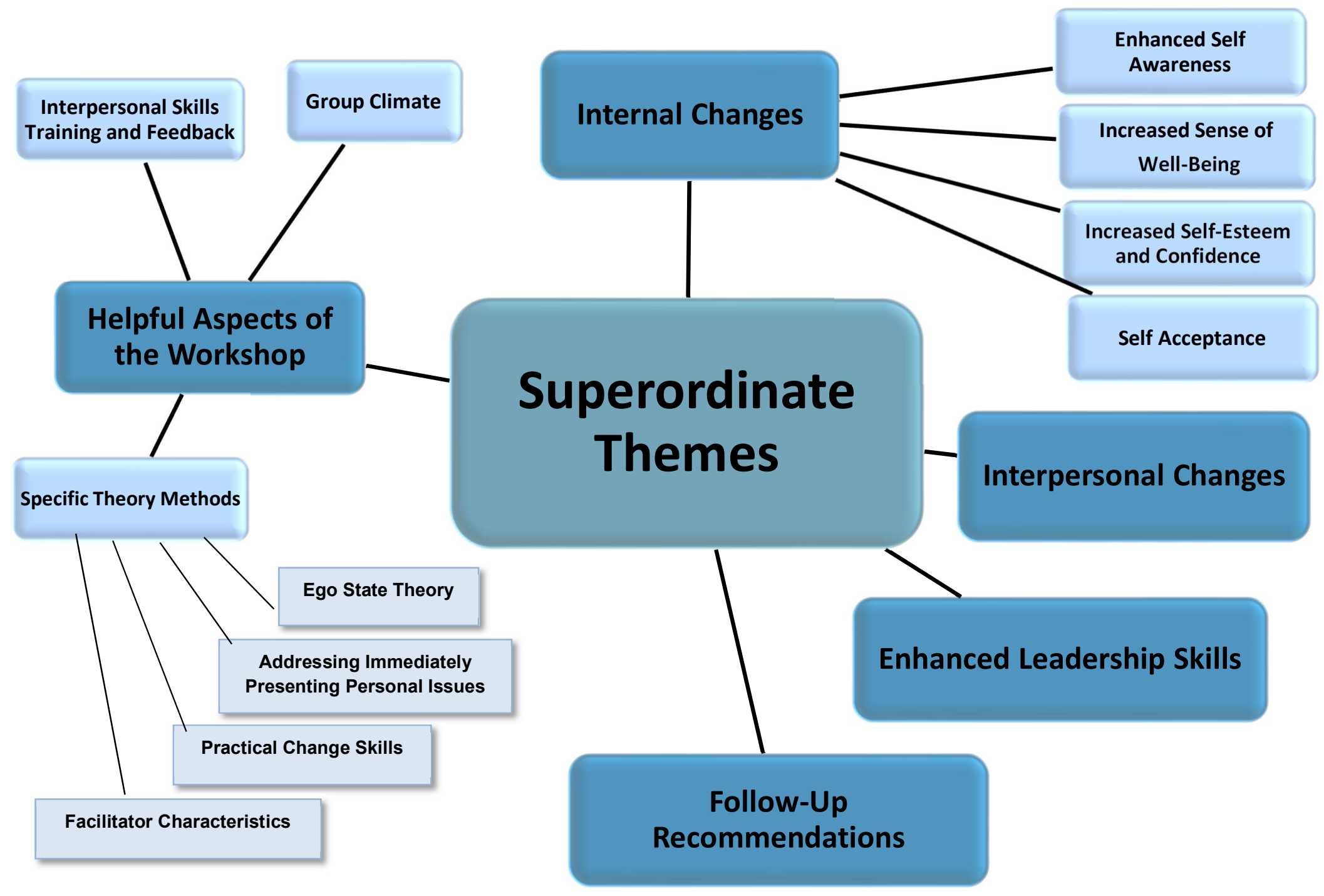


Several participants described their increased well-being as a greater sense of self-efficacy, which was combined with a healthy acceptance of their limitations and circumstances and a more assertive approach with others:

I no longer feel frustrated because of things out of my control, I learnt to say "no" to things/people and stopped over-loading myself

\subsection{Increased Self-Esteem and Confidence}

Typically, participants reported increased self-esteem and an improved sense of self-confidence which in turn has increased the level of esteem other people hold them in:

I have grown into someone I am proud of and who many of my friends and colleagues on peer level come to for advice and coaching - both personally and privately.

I am doing well and I started to really believe in myself. I guess I am more attentive to every progress I am making and try to celebrate a success as well, instead of already thinking of the next steps and points I need to tackle.

In this quote, the participant identifies a process of increased accounting for their development which led to a greater sense of pride and achievement.

\subsection{Self-Acceptance}

The theme of self-acceptance was commonly reported, with participants becoming increasingly selfcompassionate and accepting of their imperfections:

I am feeling good about myself....not like there's something "wrong" or "to fix" about me. I started giving myself several "permissions to."

I am not so harsh on myself and this has definitely changed my outlook on life

Another participant described this process of selfacceptance and acceptance of flaws and weaknesses as:

I learnt that people can love me or like me even if I show my weaknesses and I also learnt that I don't always need to be perfect

This acceptance of imperfections was a sharp contrast for these participants against their previously held views that imperfections were to be hidden and eradicated. Two respondents reported specific changes relating to an increased sense of self-acceptance which also had a positive impact on their interpersonal relationships.

Something else that changed and is very important to me is the fact that I no longer take criticism personally. This is a consequence of not expecting perfection from myself anymore and accepting the fact that I have flaws and certain aspects of me are not going to be liked by others. It's not that I don t care anymore.... I still work on myself, search feedback and act upon it but I don t crucify myself over it now! At the beginning of the training receiving negative feedback would have kept me up for nights trying to figure out what I did wrong... now I just accept it and look for solutions to improve without blaming myself.

In this quote, the participant clearly describes how letting go of perfectionism and developing self-acceptance has given them greater resilience and increased capacity to receive negative feedback and find a greater sense of perspective over others perceptions of them.

Superordinate Theme 2: Interpersonal Changes All of the respondents reported positive interpersonal changes, many of which have already been referred to in previous quotes or will be discussed below. One participant described an interesting process of increased ability to mutually interact with others:

My thinking process also changed: I no longer have a $100 \%$ internal locus of control: I acknowledge that other people also influence the general output. By only changing myself I won't be getting all the results that I want. My behaviour changed: I learnt to influence, engage and negotiate in a more effective way. Now I am a lot more capable of reaching results through others

\section{Superordinate Theme 3: Enhanced Leadership Skills}

Participants also typically reported enhanced leadership skills. These were primarily interpersonal in nature and did not tend to refer to increased productivity, although it is likely that they did have a positive impact on the productivity levels of their teams.

An unexpected side-effect of the training is that I am able to considerably reduce passive behaviours in my team, hence be a lot more effective in problem solving.

Although this participant described an improvement in their ability to handle issues in their team, unfortunately they did not specify how they had implemented this change. This improvement in leadership ability was reflected by another participant, who also did not specify how their skills had improved:

The feedback from the rest of the organisation is also very good: I am seen as a fair and credible counterpart with a very mature leadership style. My role provides support to over 320 people so I have plenty of feedback!

Superordinate Theme 4: Helpful aspects of the workshop

4.1: Group Climate:

All participants identified the group climate to have been particularly helpful in promoting change. The group 
climate was characterised by high levels of participation and openness, and also a sense of belonging:

What also helped was having people that are undergoing the same process as you that keep you motivated and included, part of a community.

In this quote, the participant suggests that the group members had a mutually motivating effect on each other to support each other's change process. The experience of inclusion and belonging and a willingness to be open and vulnerable was one which was highly valued by almost all of the respondents. The element of inclusion appears to have encompassed the valuing of each member's participation in the group experience as both a giver and recipient of helpful feedback.

The contribution of every participant of the training, the open discussions helped a lot. Especially the first round concerning the perception and the last round with the feedbacks were surprisingly super impactful.

\subsection{Interpersonal Skills Training and Feedback:}

Five participants stated that the aspects of the workshop which focused on interpersonal skills training had been helpful, and in particular, getting direct and immediate feedback from the facilitator and other participants.

The training made me see how others perceived me and how little I was willing to do to meet new people

One participant reflected on their interpersonal changes and how these had come about and stated that:

The other most important factor in bringing these changes is that I had someone help me envision these changes (what needed to be changed, the cause behind it, what would change look like) and, fundamentally, that FOR THE FIRST TIME EVER gave me the tools (real ones, practical, hard ones) to act on change .

Here it seems that the facilitator's influence was central in providing a model for change by helping the participant clarify what their problems were and their origins, identify contract goals and suggest a direction for change. This is in keeping with the redecision model used in the workshops as described in the article by Rosseau et al (2014). In particular, the participant appears to be emphasizing that the change process did not just involve insight, but also specific actions.

Increased self-awareness, self-efficacy, a sense of direction for change and a pro-social desire to help others were also raised:

Probably the best training in my career. I really do feel that I went home from the training with a better understanding of myself, where I want to go, and as well with the skills to support my colleagues and friends in finding their path on the job and privately

This pro-social outcome characterized by increased desire to help others has links to superordinate Theme 2: Interpersonal Changes) and superordinate Theme 3: Enhanced Leadership Skills; participants reported desirable changes in their way of relating to others which enhanced their ability to manage the interpersonal demands of their role. This is an interesting finding, as the use of a therapeutic approach which emphasises personal responsibility and individual change might not be immediately expected to produce such outcomes.

The negotiation exercise is something I really remember as if it was yesterday. Maybe because it was fun but also because I think it exhibited how difficult it can be to come to an agreement when you don't see/sense where the other person is coming from.

In this quote, the participant expresses the value of interpersonal learning components of the workshop as being helpful in improving their ability to successfully negotiate with others.

The combination of group climate, a focus on selfawareness and developing interpersonal skills is also mentioned by this participant:

The fact that, on the training, you get time for selfinvestigation as well as honest feedback from the group. This gave me the necessary time to get some perspective and brought along the extra perspective from the group... It gave me tools I have actively used which is also why I believe the change happened, because I made it become alive.

Again, the group gave participants an opportunity to experiment with new ways of being in the here-and-now and experience immediate and direct interpersonal feedback on these new behaviours or ways of relating to others.

\subsection{Specific Theory/Methods: (Use of therapy interventions)}

\subsubsection{Ego State Theory}

Two respondents identified ego state theory as being helpful:

The exercises with the ego states gave me good insights to different people I worked with at that point in time and to myself in different situations both now and then.

Unfortunately, these participants did not provide further specific information regarding how ego state theory had been helpful or how they had used this theory outside of the workshop. 
At first, I thought these circles were too good to be true. But, they really work. I can easily read people and understand myself.

Here we see that the participant is clearly stating how learning ego state theory has both enhanced their own self-awareness and also provided a method for increasing their interpersonal understanding. The use of phrases such as 'too good to be true' and 'easily' give the impression that the model was easy to implement and that the results the participant experienced from using this aspect of transactional analysis theory was pleasantly surprising.

\subsubsection{Addressing immediately presenting personal issues:}

Two mentioned that they had contracted for and engaged in a piece of personal therapy as specific issues had emerged in the group, and that they had found this to be helpful.

\subsubsection{Practical Change Skills:}

Two respondents stated that the workshop had given them practical change skills, but did not specify what these were.

Changing aspects so deep of your personality is the most difficult thing to do.....and most of the time you feel helpless and frustrated. . . [the facilitator] gave me tools that empowered me, that made me curious to try them out, that were very easy to test and that gave me quick wins to keep me going!

In this quote, the participant explicitly states that despite recognising how difficult they felt deep change work to be, they felt empowered by the approach used. It would appear that the facilitator worked to activate their interest and motivation to take the first steps into personal change, and that each successive small change was identified and celebrated which continued to motivate the participant to continue with the process.

\subsection{Facilitator Characteristics: Observation, Assessment and Permission}

Five participants specifically raised the facilitator's characteristics as being a key factor in the success of the workshop. In particular, these participants stated that they had valued the facilitator's ability to observe individuals and the group, make an assessment and then use this to guide the intervention.

Specifically, one participant stated that the facilitator never left us in our comfort zones but knew exactly how far outside to push us.
Another participant described the facilitator's identification of their core vulnerabilities and a permissive stance which promoted change:

I think the most influential thing for me during the training was (the facilitator's) ability to see what you cover/hide deep inside. Usually it is your "weak" parts, or just something that makes you less strong and more vulnerable, it may be fear, anger, shyness, different complexes, etc. Once he noticed my "inner layers", which in my opinion were weaknesses, and said that it is ok to be imperfect, it is ok to relax, I was really impressed. Just because he understood me or read me as a book so well and gave food for thoughts... (following this, I reflected on my way of being and) I thought maybe it is time to relax, to change, to share emotions and even to fail. It is time to let it go and be imperfect.

\subsection{Follow-Up Recommendations}

Four participants stated that they had found individualised recommendations for further reading had been helpful in consolidating their changes, although they did not specify what the recommended reading was.

\section{Discussion}

The findings in the study are broadly in line with previous research. As with the studies conducted by Olivero et al. (1997) Kampa-Kokesch \& Anderson, (2001), Evers et al (2006) and Kombarakan at al (2008), participants in the coaching workshops experienced personal growth, improved work performance, positive interpersonal changes and increased self-efficacy. The findings also broadly support the existing transactional analysis literature on redecision therapy-based groups which found improvements in communication and personal growth (McNeel, 1982), and increased self-esteem (Noriega Gayol, 1997). This suggests that transactional analysis provides an appropriate framework for conducting such coaching workshops and that results obtained in clinical settings may also be applicable to the use of redecision methods in a business setting.

In business, managers use models to do a health check of their organisation. In Europe, the European Foundation for Quality Management (EFQM) (2013) approach is widely used. The model helps businesses to check how they perform on different elements. Four areas for observation deal with components of output and five areas for observation measure factors that enable those results. The entire cycle is supported by innovation and learning. We think that, upon adaption of the EFQM-model for total quality, it must be possible, and above all, beneficial to create such an observation grid for psychological interventions, regardless of the area of application. So far, most research tries to find a connection between an approach on the one hand and the results on the other. We recommend to also develop a more Holistic view that puts more emphasis on many 
components, rather than looking for a cause-and-effect relationship. Enablers are intervention planning, flexibility in methodology, autonomy of the coach. Under results we could put the level of cure, social results, professional results.

The EFQM approach has helped a large number of businesses and organisations to diagnose where the areas for improvement are, and 'cure' them. We think that using a RADAR (European Foundation for Quality Management 2013) as a structured way of looking at psychological intervention processes, can be beneficial not only for the coach/therapist/teacher but also for research purposes. The reader will have noticed that in this article, we still mix enablers and results. Of course, there is a connection between both, but maybe, looking for a linear connection, we blind ourselves to important parts of the bigger picture.

transactional analysis, as a model for applied psychology and a set of intervention tools, already has a holistic view. As enablers, we have contracting, continuous training, partnerships and shared resources. In the result area, we have different ways of measuring success.

It would be fascinating to have an instrument that, regardless the field of application, regardless of the specific focus (transactional analysis schools), helps us to improve both the enablers and the results, with that supported by innovation and learning.

\section{Limitations}

The participants were a convenience sample who were approached by the second author to take part in the research. Although an attempt was made to ensure the sample was as representative as possible, it is nevertheless possible that some selection bias occurred in the sampling process.

It is also possible that transferential artefacts such as a desire to please the workshop facilitator unduly influenced the responses. This possibility was increased due to the fact that participants sent their responses directly to the second author instead of to the first author who was a neutral and independent researcher.

These potential sources of bias are a major limitation of this study, and in further research it would be desirable to address this by arranging for the selection and participant contact to be conducted directly by an independent researcher who was not involved in the delivery of the workshops.

The use of a questionnaire tool instead of an interview resulted in some limitations in the available data. The feedback which was provided at times lacked specificity; this could have been addressed in an interview format where greater probing could have taken place. This limitation in the data clearly had an impact by limiting the findings to provision of a preliminary view of what changes the participants experienced and how those changes come about. Nevertheless, the commonality amongst participants' feedback is notable and adds to the trustworthiness of the findings.

The importance of transactional analysis as a guiding framework for the workshops is unclear, and although a number of participants did specifically mention the theory of ego states as being helpful, it is not possible to state that transactional analysis played a major part in the process due to the relative lack of specific data relating to transactional analysis theory or processes.

\section{Conclusions}

The findings of this study suggest that transactional analysis, and specifically the use of redecision methods, can provide an effective framework for executive coaching workshops delivered in a business environment. Participants experienced a wide range of personal growth experiences, which included increased self-awareness, increased self-acceptance and positive interpersonal change.

Participants also experienced positive growth in their business and leadership skills as a result of participating and reported that this increased their professional effectiveness which in turn had a beneficial effect on their management skills and overall team productivity levels.

In light of the high levels of personal growth experienced by participants, a further study which specifically measures positive change and personal growth using a standardised outcome tool is warranted. This is being planned and it is hoped that it will enable specific quantitative evaluation of the effectiveness of the workshop method.

Mark Widdowson $\mathrm{PhD}$ is a Teaching and Supervising Transactional Analyst (Psychotherapy) and a lecturer in counselling and psychotherapy at the University of Salford. He can be contacted on mark.widdowson1@btopenworld.com.

Mil Rosseau is a Certified Transactional Analyst (Educational).

\section{References}

Boholst, F. A. (2003). Effects of transactional analysis group therapy on ego states and ego state perception. Transactional Analysis Journal, 33(3): 254-61.

Braun, V., \& Clarke, V. (2006). Using thematic analysis in psychology. Qualitative Research in Psychology, 3 (2), 77-101.

Coopersmith, S. (1981). The antecedents of self-esteem. Palo Alto, CA: Consulting Psychologists Press. (Original work published 1967). 
Elliott, R., Slatick, E., and Urman, M. (2001). Qualitative Change Process Research on Psychotherapy: Alternative Strategies. In: J. Frommer and D.L. Rennie (Eds.), Qualitative psychotherapy research: Methods and methodology (pp. 69-111). Lengerich, Germany: Pabst Science Publishers.

European Foundation for Quality Management (2013) The EFQM Excellence Model http://www.efgm.org/the-efamexcellence-model accessed 11/12/2013

European Foundation for Quality Management (2013) RADAR http://www.efam.org/efam-model/radar-logic accessed $11 / 12 / 2013$

Evers, W.J.G., Brouwers, A. \& Tomic, W. (2006). A quasiexperimental study on management coaching effectiveness. Consulting Psychology Journal: Practice and Research, 58(3): 174-182

Goulding, M.M. and Goulding, R.L (1979). Changing lives through redecision therapy. New York: Grove Press.

Hart, V., Blattner, J. \& Leipsic, S. (2001). Coaching versus therapy: a perspective. Consulting Psychology Journal: Practice and Research, 53(4): 229-237.
Kampa-Kokesch, S \& Anderson, M.Z. (2001). Executive coaching: a comprehensive review of the literature. Consulting Psychology Journal: Practice and Research, 53(4): 205-228.

Kombarakan, F.A., Yang, J.A., Baker, M.N. \& Fernandez, P.B. (2008). Executive coaching: it works! Consulting Psychology Journal: Practice and Research, 60(1): 78-90.

McNeel, J.R., (1982). Redecisions in psychotherapy: a study of the effects of an intensive weekend group workshop. Transactional Analysis Journal, 12(1): 10-26.

Noriega Gayol, G. (1997) Diagnosis and treatment of ego state boundary problems: effects on self-esteem and quality of life. Transactional Analysis Journal, 27(4): 236-40.

Olivero, G., Bane, K. D., \& Kopelman, R. E. (1997). Executive coaching as a transfer of training tool: Effects on productivity in a public agency. Public Personnel Management, 26(4) 461-469.

Rosseau, M, Rosseau, R \& Widdowson, M (2014) Application of Redecision Therapy in Executive Coaching Workshops: Part 1 the Workshop International Journal of Transactional Analysis Research 5:1 15-19 
Appendix 1: Change Questionnaire

Adapted by Mark Widdowson from Elliott et al (2001)

\section{General Questions:}

1a. What other trainings have been influential for you?

1b. What has the training-effect been like for you so far? Please check thinking, feeling and behaviour.

1c. In general terms, how are you doing now?

Professionally

Privately

\section{Changes:}

2a. What changes, if any, have you noticed in yourself after the training? (For example, are you doing, feeling, or thinking differently from the way you did before? What specific ideas or new ways of thinking about things, if any, have you got from the training so far, including ideas about yourself or other people? Have any changes been brought to your attention by other people?) Please also list these changes on the table on the next page. Please feel free to add more if you wish.

2b. Has anything changed for the worse for you since you took the training?

2c. Is there anything that was in your training contract that hasn't changed since the training started?

\begin{tabular}{|l|l|l|l|}
\hline $\begin{array}{l}\text { The changes I have made since } \\
\text { starting the training }\end{array}$ & $\begin{array}{l}\text { The change was: } \\
\text { 1 Expected } \\
\text { 3 Neither } \\
\text { 5 Surprising }\end{array}$ & $\begin{array}{l}\text { Without therapy the } \\
\text { change was: } \\
1 \text { Unlikely } \\
3 \text { Neither } \\
\text { 5 Likely }\end{array}$ & $\begin{array}{l}\text { The importance of this } \\
\text { change for me: } \\
1 \text { Not at all } \\
\text { 2 Slightly } \\
3 \text { Moderately } \\
4 \text { Very } \\
5 \text { Extremely }\end{array}$ \\
\hline 1 & 12345 & 12345 & 12345 \\
\hline 2 & 12345 & 12345 & 12345 \\
\hline 4 & 12345 & 12345 & 12345 \\
\hline 5 & 12345 & 12345 & 12345 \\
\hline
\end{tabular}

\section{Change Ratings:}

(Go through each change you have identified that you have made since starting the training and rate each one on the following three scales:)

3a. For each change, please rate how much you expected it vs. how much you were surprised by it? (Use this rating scale:)

(1) Very much expected it

(2) Somewhat expected it

(3) Neither expected nor surprised by the change 
(4) Somewhat surprised by it

(5) Very much surprised by it

3b. For each change, please rate how likely you think it would have been if you hadn't been in this training? (Use this rating scale :)

(1) Very unlikely without therapy (clearly would not have happened)

(2) Somewhat unlikely without therapy (probably would not have happened)

(3) Neither likely nor unlikely (no way of telling)

(4) Somewhat likely without therapy (probably would have happened)

(5) Very likely without therapy (clearly would have happened anyway)

3c. How important or significant to you personally do you consider this change to be? (Use this rating scale :)

(1) Not at all important

(2) Slightly important

(3) Moderately important

(4) Very important

(5) Extremely important

4. Attributions

In general, what do you think has caused these various changes? In other words, what do you think might have brought them about? (Including things both outside of training and in training)

\section{Helpful Aspects}

Can you sum up what has been helpful about the training so far?

Please give examples. (For example, general aspects, specific events)

6. Problematic Aspects

6a. What kinds of things about the training have been hindering, unhelpful, negative or disappointing for you? (For example, general aspects. specific events)

6b. Were there things in the training which were difficult or painful but still OK or perhaps helpful? What were they?

6c. Has anything been missing from this training? (What would make/have made your training more effective or helpful?)

7. Suggestions

Do you have any suggestions for us, regarding the research on the training?

Do you have anything else that you want to tell me? 